\title{
Reconstruction of remote climate change from borehole temperature measurement in the eastern part of Morocco
}

\author{
A. E. Barkaoui • A. Correia • Y. Zarhloule • A. Rimi • \\ J. Carneiro • M. Boughriba • M. Verdoya
}

Received: 20 December 2011 / Accepted: 11 November 2012 / Published online: 22 November 2012

(C) Springer Science+Business Media Dordrecht 2012

\begin{abstract}
Data from temperature measurements in boreholes are indicators of the temperature variations associated with past climate change. This paper is a contribution to reconstruct the ground surface temperature history (GSTH) from geothermal data in the eastern part of Morocco. From a set of several temperature logs, measured in the study area, only two were found suitable for estimating the ground surface temperature history (GSTH). In order to reconstruct the surface temperature past changes the functional space inversion method (FSI) was used. The inversion reveals a recent warming in the last century with respective amplitude of $0.1{ }^{\circ} \mathrm{C}$ and $1{ }^{\circ} \mathrm{C}$ for the boreholes 2952 in Oujda and 1624 in Berkane. These results can be confirmed by the air temperature record of the meteorical station in Oujda despite the scarceness of data beyond 1959.
\end{abstract}

\section{Introduction}

In recent years, geothermal methods have been used to provide additional evidence for recent climatic changes in several parts of the world (Pollack 2000; Bodri and Cermak 2007; González-Rouco et al. 2009). The thermal regime of the solid Earth is a function of the heat flow from the Earth's interior and the temperature at its surface. Under normal condition, the heat flow change on time scales of $10^{6}$ years, well beyond the ones relevant to borehole

A. E. Barkaoui $(\bowtie) \cdot$ Y. Zarhloule $\cdot$ M. Boughriba

Laboratory of Hydrogeology-Environment, Faculty of Sciences, University Mohamed Ist, Oujda, Morocco e-mail: barkalae@yahoo.fr

A. Correia $\cdot$ J. Carneiro

Department of Geosciences, Geophysical Centre of Évora, University of Évora, Évora, Portugal

A. Rimi

University Mohammed V-Agdal, Scientific institute, Rabat, Morocco

M. Verdoya

Dipartimento per lo Studio del Territorio e delle sue Risorse, Università di Genova, Genoa, Italy 
climatic studies. Therefore it can be treated as constant in this case. The heat flow is represented by Fourier's law:

$$
q=-k d T / d z
$$

$$
\begin{array}{ll}
\mathrm{q} & \text { Heat flow density }\left(\mathrm{mW} / \mathrm{m}^{2}\right) \\
\mathrm{k} & \text { Thermal conductivity }(\mathrm{W} / \mathrm{m} \cdot \mathrm{K}) \\
\mathrm{dT} / \mathrm{dz} & \text { Geothermal gradient }(\mathrm{G})(\mathrm{K} / \mathrm{m}) .
\end{array}
$$

From the surface the variation in the temperature propagate downward into the subsurface by thermal conduction creating transitory disturbances in the geothermal gradient. The velocity of disturbance is a function of the thermal diffusivity of the rocks (K). The skin depth depends on the period oscillation in such way that the low-frequency waves propagate deeper than higher frequency components. The problem of subsurface temperature disturbance can be resolved with the use of the one-dimensional heat diffusion equation in homogenous medium (Carslaw and Jaeger 1962):

$$
\partial T / \partial t=\alpha \partial^{2} T / \partial z^{2}
$$

When studying the perturbations of subsurface temperature by changes of ground surface temperatures, it is common practice to construct a reduced temperature. This is done by extrapolating to the surface to determine $\mathrm{T}_{0}$ (Fig. 1), the average gradient of the deepest portion of the thermal profile which represents, in the case of a steady heat transfer, a heat flow from the earth's interior. Heat transport by fluid flow may disturb the in situ thermal conditions. Also, the effects of older climate change, e.g., the last ice age, maybe present,

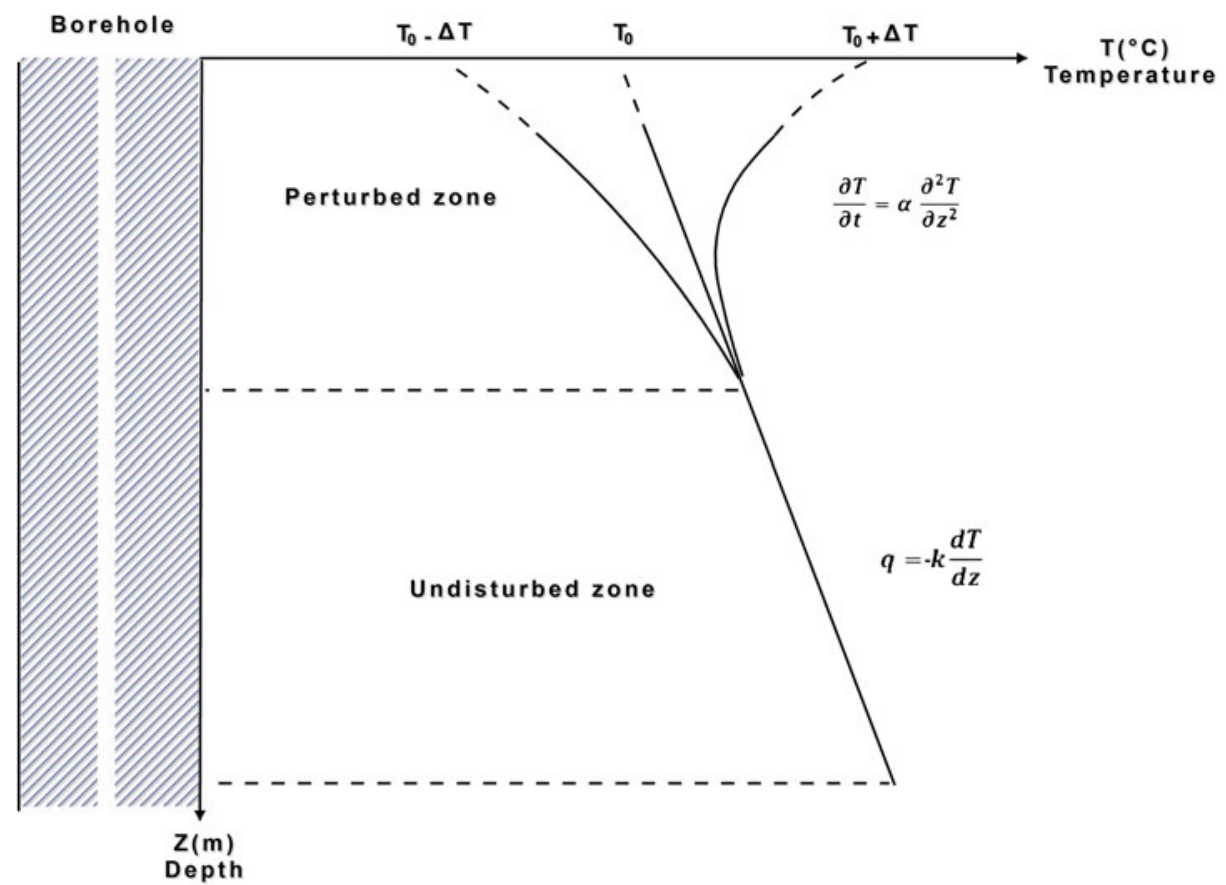

Fig. 1 Result of the surface change on the subsurface temperature. Bottom: Typical temperature-depth profile measured in a borehole. Top: perturbation on the geothermal gradient 


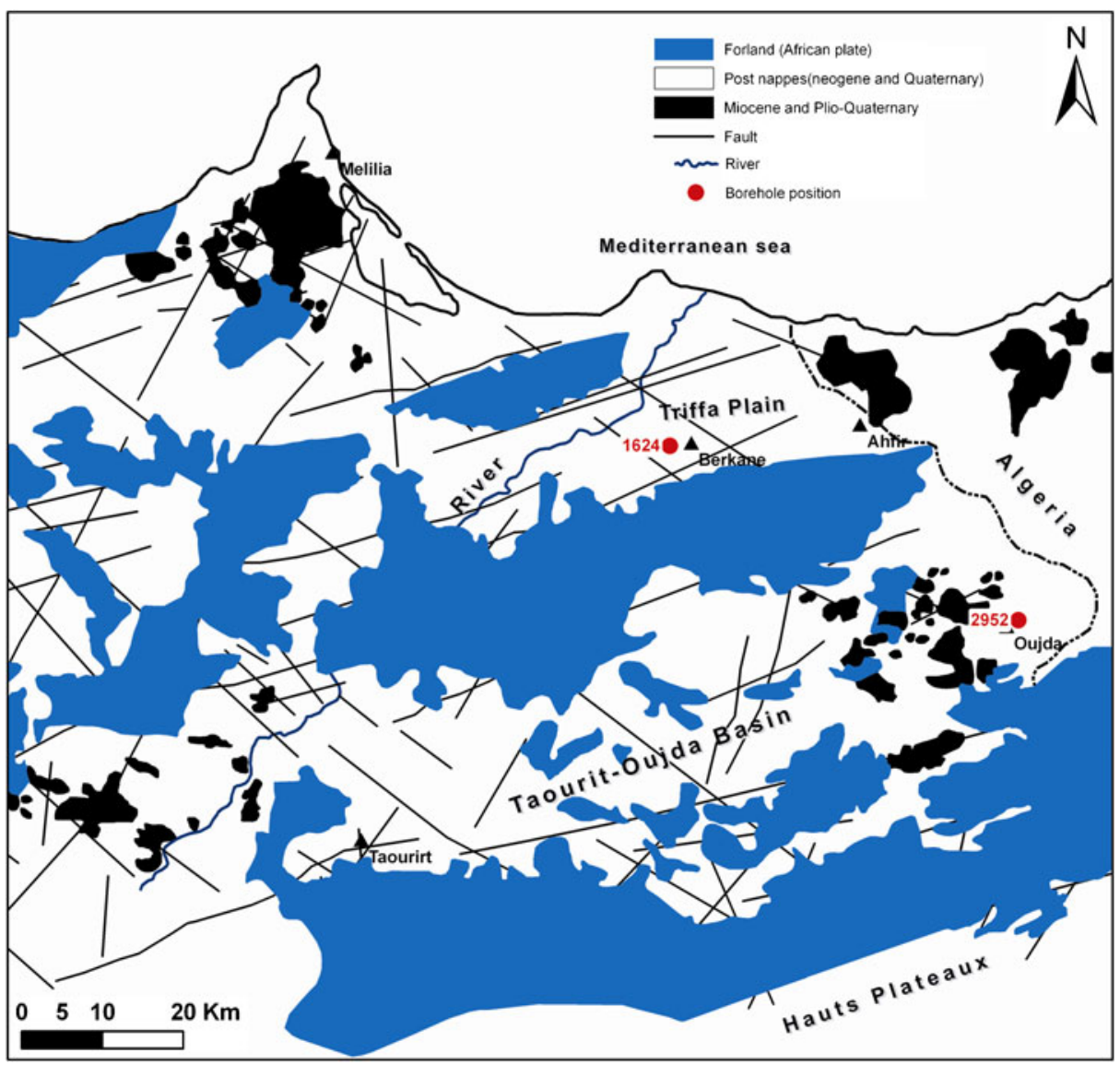

Fig. 2 Simplified geological map of Northeastern Morocco showing the locations of the boreholes studied for climate change reconstruction

and should be taken into account at depths where they can no longer reasonably be well approximated by a linear behavior (see Rath et al. 2012). The initial conditions at $t=0$, can be expressed as:

$$
T(z, 0)=T_{0}+G_{0} z
$$

$\mathrm{T}_{0} \quad$ is the undisturbed original temperature

$\mathrm{G}_{0}$ is the geothermal gradient

In the other case when the surface temperature changes with time, the subsurface temperature will depart from the linear distribution. A progressive cooling at the surface will increase the temperature gradient at shallow depth $\left(\mathrm{T}_{0}-\Delta \mathrm{T}\right)$, while a progressive warming will result in a smaller gradient or even a negative gradient at shallow depths $\left(\mathrm{T}_{0}+\Delta \mathrm{T}\right)$.

Different physical processes, like temporal changes of thermal conductivity, historical presence of water bodies or ice sheets, or changes of vegetation (land use) (Bense and 
Table 1 Underground temperatures measured in the borehole 2952/12

\begin{tabular}{|c|c|c|c|c|c|c|c|c|c|c|c|}
\hline $\mathrm{T}\left({ }^{\circ} \mathrm{C}\right)$ & Depth(m) & $\mathrm{T}\left({ }^{\circ} \mathrm{C}\right)$ & Depth(m) & $\mathrm{T}\left({ }^{\circ} \mathrm{C}\right)$ & $\operatorname{Depth}(\mathrm{m})$ & $\mathrm{T}\left({ }^{\circ} \mathrm{C}\right)$ & Depth(m) & $\mathrm{T}\left({ }^{\circ} \mathrm{C}\right)$ & $\operatorname{Depth}(\mathrm{m})$ & $\mathrm{T}\left({ }^{\circ} \mathrm{C}\right)$ & Depth(m) \\
\hline 22.16 & 47 & 24.55 & 91 & 26.95 & 135 & 29.35 & 179 & 31.91 & 223 & 34.45 & 267 \\
\hline 22.21 & 49 & 24.68 & 93 & 27.05 & 137 & 29.45 & 181 & 32.02 & 225 & 34.54 & 269 \\
\hline 22.29 & 51 & 24.81 & 95 & 27.14 & 139 & 29.55 & 183 & 32.13 & 227 & 34.67 & 271 \\
\hline 22.38 & 53 & 24.94 & 97 & 27.25 & 141 & 29.68 & 185 & 32.25 & 229 & 34.78 & 273 \\
\hline 22.48 & 55 & 25.06 & 99 & 27.35 & 143 & 29.79 & 187 & 32.38 & 231 & 34.88 & 275 \\
\hline 22.57 & 57 & 25.17 & 101 & 27.45 & 145 & 29.91 & 189 & 32.48 & 233 & 35.01 & 277 \\
\hline 22.68 & 59 & 25.29 & 103 & 27.56 & 147 & 30.05 & 191 & 32.60 & 235 & 35.11 & 279 \\
\hline 22.77 & 61 & 25.43 & 105 & 27.66 & 149 & 30.16 & 193 & 32.71 & 237 & 35.22 & 281 \\
\hline 22.89 & 63 & 25.53 & 107 & 27.77 & 151 & 30.27 & 195 & 32.82 & 239 & 35.33 & 283 \\
\hline 23.02 & 65 & 25.63 & 109 & 27.87 & 153 & 30.40 & 197 & 32.94 & 241 & 35.43 & 285 \\
\hline 23.13 & 67 & 25.73 & 111 & 28.00 & 155 & 30.53 & 199 & 33.06 & 243 & 35.56 & 287 \\
\hline 23.25 & 69 & 25.83 & 113 & 28.07 & 157 & 30.66 & 201 & 33.15 & 245 & 35.66 & 289 \\
\hline 23.38 & 71 & 25.94 & 115 & 28.18 & 159 & 30.79 & 203 & 33.27 & 247 & 35.78 & 291 \\
\hline 23.50 & 73 & 26.05 & 117 & 28.30 & 161 & 30.91 & 205 & 33.38 & 249 & 35.88 & 293 \\
\hline 23.64 & 75 & 26.16 & 119 & 28.40 & 163 & 31.03 & 207 & 33.51 & 251 & 35.99 & 295 \\
\hline 23.73 & 77 & 26.25 & 121 & 28.52 & 165 & 31.14 & 209 & 33.62 & 253 & 36.10 & 297 \\
\hline 23.85 & 79 & 26.36 & 123 & 28.66 & 167 & 31.25 & 211 & 33.74 & 255 & 36.20 & 299 \\
\hline 23.97 & 81 & 26.46 & 125 & 28.78 & 169 & 31.36 & 213 & 33.85 & 257 & - & - \\
\hline 24.08 & 83 & 26.56 & 127 & 28.89 & 171 & 31.46 & 215 & 33.96 & 259 & - & - \\
\hline 24.20 & 85 & 26.65 & 129 & 29.00 & 173 & 31.58 & 217 & 34.10 & 261 & - & - \\
\hline 24.31 & 87 & 26.76 & 131 & 29.14 & 175 & 31.68 & 219 & 34.19 & 263 & - & - \\
\hline 24.44 & 89 & 26.86 & 133 & 29.24 & 177 & 31.78 & 221 & 34.32 & 265 & - & - \\
\hline
\end{tabular}

Beltrami 2007) may also contribute to the signal present in the subsurface. For the boreholes chosen for paleoclimatic interpretation, we assume that the contributions of the kind listed can be safely neglected.

\section{Borehole temperature logging and inversion method}

The sedimentary formations in northeastern Morocco units contain hot reservoirs. The most important aquifer is formed by Liassic carbonates with a thickness up to $500 \mathrm{~m}$. With the objective of improving the geothermal dataset and gaining a better insight into the geothermal potential of the study area, many exploratory geothermal surveys were conducted in the past based on hydraulic and mining boreholes. The results obtained from these surveys demonstrate the generally increased geothermal gradient in the area (Zarhloule 1999).

In 2007, new thermal logs were performed in boreholes located in Oujda and Berkane region (Fig. 2). The obtained thermal profiles were used to study the climatic signal stored in the underground. The choice of those boreholes was made according to some conditions:

1. The observed temperature gradient at a given depth includes the effects of past surface temperature changes, superposed on the purely "geothermal" gradient. In order to reliably estimate the geothermal gradient, and thus separate it from the recent climatic signal, boreholes must be deep enough. 
2. We used only boreholes which can be assumed to have equilibrated with the ambient rock temperatures. Measurements were performed after 27 years from drilling for the borehole 2952/12 and 10 years for the borehole 1624/7.

3. The temperature measurements in the two boreholes were free from perturbations related to groundwater movement, and therefore provide an ideal setting to interpret changes in subsurface temperatures in terms of changes in surface ground temperatures.

Temperature measurements were carried out using thermistor probe connected to a cable that goes down. An ohmmeter measure the resistance of the thermistor every 2$\mathrm{m}$. To guarantee the equilibrium of the thermistor with the environment, it was left for few minutes in each position before measuring. The thermistor have a low calorific capacity and can be adapts easily to the temperature of the formation. Table 1 shows the data recorded in the borehole $2952 / 12$, the lithological log is formed by conglomerate, followed by the intercalation of marl and sandstone until the depth of $580 \mathrm{~m}$ where we reach the mean Liasic geothermal reservoir formed by limestone (Fig. 3a). The temperature log in Fig. 4a outlines the variation in the geothermal gradient at around $580 \mathrm{~m}$, for this borehole only the uppermost section, from 47 to $299 \mathrm{~m}$, was used for inversion. In the borehole 1624/7 the lithology changes at around $300 \mathrm{~m}$ from marl to limestone (Fig. 3b). The geothermal gradient increase also at the same depth but cannot be explained only by the variation in the lithology because of the difference in the thermal conductivity. Table 2 shows temperature data, while Fig. $4 \mathrm{~b}$

a

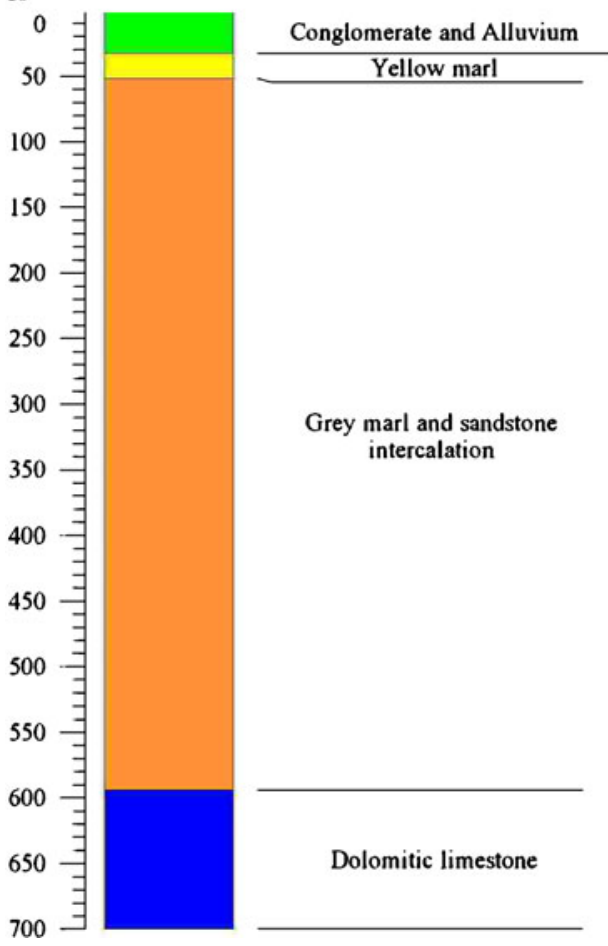

b

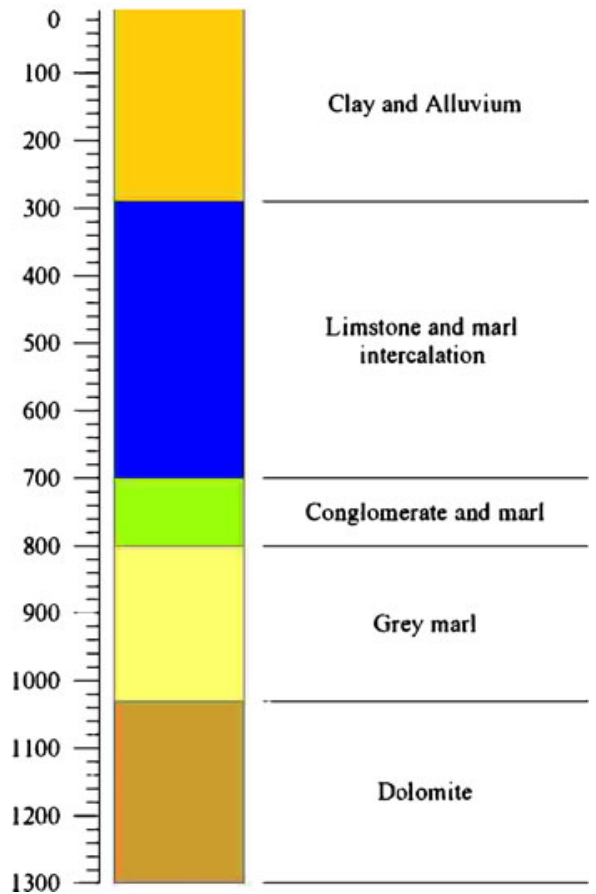

Fig. 3 a: Lithological $\log$ for the borehole 2952/12. b: Lithological log for the borehole 1624/7 


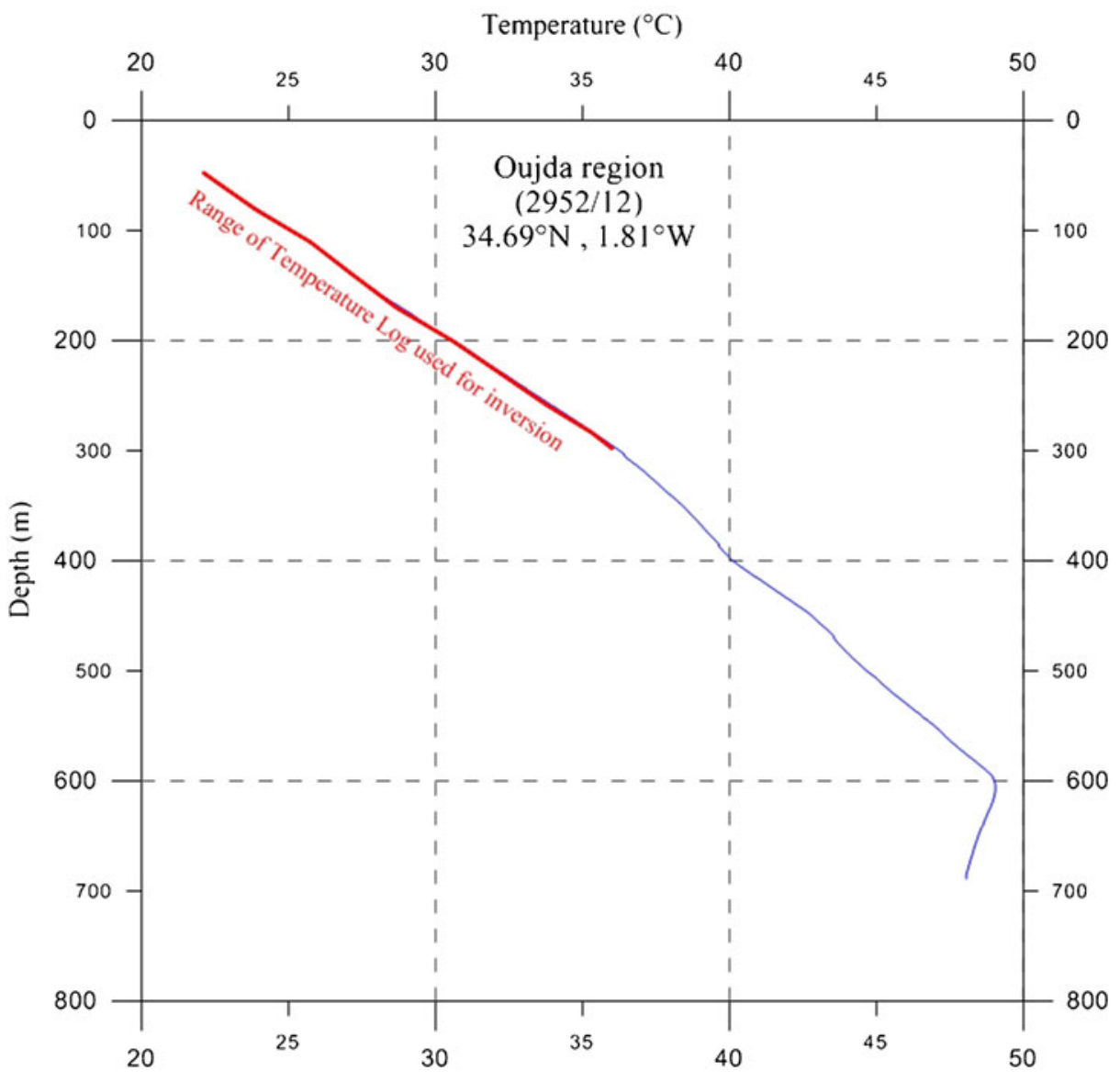

Fig. 4 a: Temperature-Depth profile selected for this study (2952/12 in Oujda). Including the section selected for inversion. b: Temperature-Depth profile selected for this study (1624/7 in Berkane). Including the section selected for inversion

depicts the temperature gradient. For the borehole 1624/7 the section between 14 and $298 \mathrm{~m}$ was used for inversion.

The reconstruction of the ground surface temperature from the subsurface temperature profiles presents an inverse problem based on the theory of 1-D heat conduction; it assumes that a spatially uniform boundary condition is applied on a plane surface and that physical properties only depend on depth. The first application of inversion techniques was done by Vasseur et al. (1983). In the last 20 years, several papers have addressed the problem of inversion of borehole temperature data and different methods have been proposed to invert the ground surface temperature history from one or several temperature profiles. In processing data, the Functional space inversion (FSI) of Shen and Beck (1991) was used. This method makes use of the nonlinear least squares theory in solving the one dimensional heat conduction equation in a layered half space. The FSI use the Bayesian approach, when both the measured temperature profile, the parameters of the physical model and the sought 


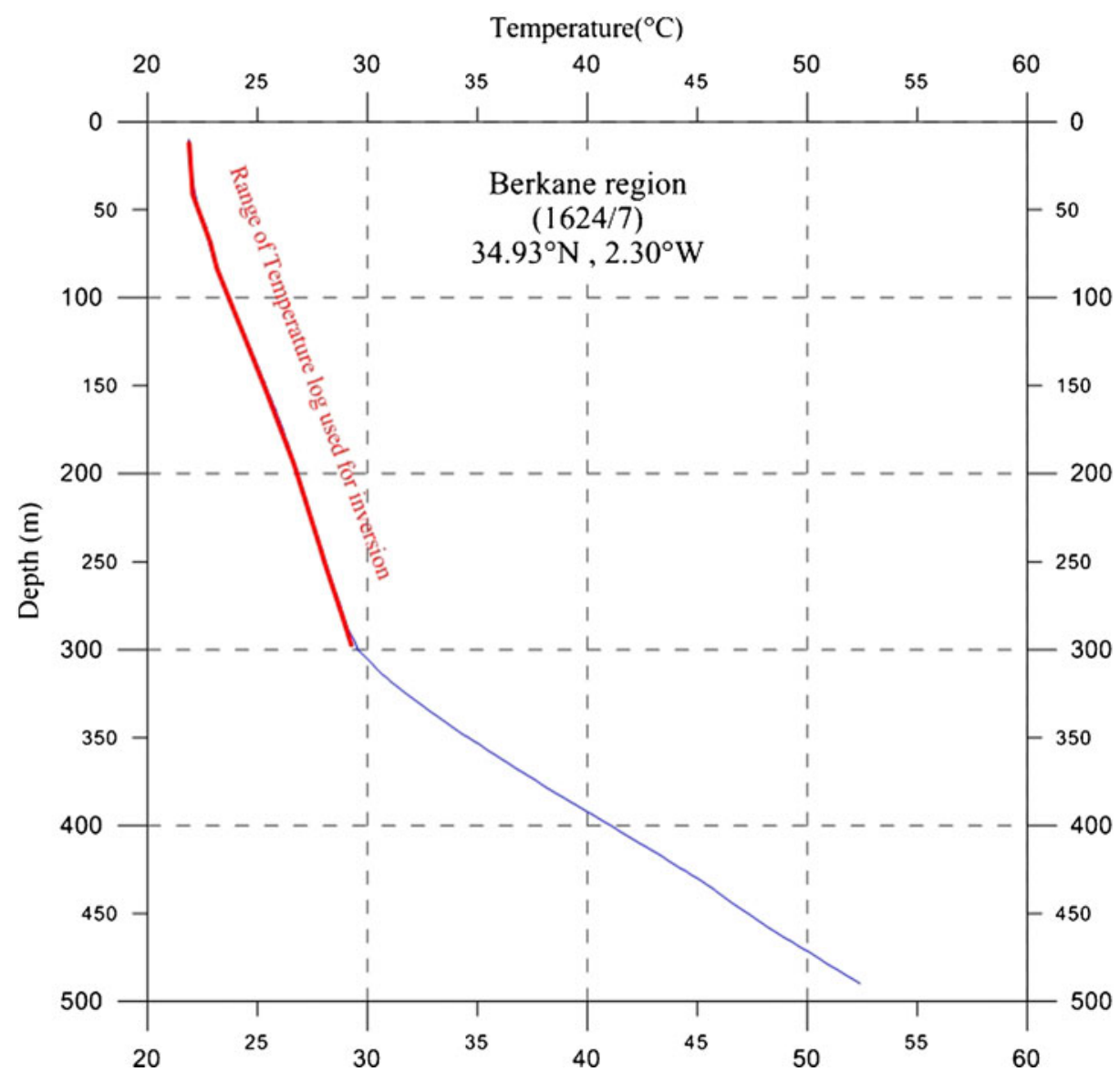

Fig. 4 (continued)

history of the surface temperature are treated as random quantities in the probabilistic model defined by a priori estimates of these quantities and their standard deviations (SDs). The a priori values are modified during the inversion in order to reach the $a$ posteriori configuration with maximum probability (Majorowicz et al. 2004).

\section{Discussion}

In northeastern Morocco, a number of measurements were carried out on a set of samples to determine the thermal diffusivity, this parameter represent the link between the present-day temperature vs depth profile and the past surface temperature history that produced that profile. The obtained results are typical for sedimentary rocks (Table 3). For the borehole $2959 / 12$, the ground surface temperature reconstruction goes to the years 1994 . The obtained signal is quite weak, and for the most conservative inversion with standard deviation of 2 and variation value of $0.1 \mathrm{~K}$, the amplitude of the recent warming is in the order of $0.1{ }^{\circ} \mathrm{C}$ (Fig. 5a). For the borehole $1624 / 7$ the paleotemperature signal is more prominent, the 
Table 2 Underground temperatures measured in the borehole 1624/7

\begin{tabular}{lllllllllllllll}
$\mathrm{T}\left({ }^{\circ} \mathrm{C}\right)$ & $\begin{array}{l}\text { Depth } \\
(\mathrm{m})\end{array}$ & $\mathrm{T}\left({ }^{\circ} \mathrm{C}\right)$ & $\begin{array}{l}\text { Depth } \\
(\mathrm{m})\end{array}$ & $\mathrm{T}\left({ }^{\circ} \mathrm{C}\right)$ & $\begin{array}{l}\text { Depth } \\
(\mathrm{m})\end{array}$ & $\begin{array}{l}\mathrm{T}\left({ }^{\circ} \mathrm{C}\right) \\
(\mathrm{m})\end{array}$ & $\begin{array}{l}\text { Depth } \\
\mathrm{T}\left({ }^{\circ} \mathrm{C}\right)\end{array}$ & $\begin{array}{l}\text { Depth } \\
(\mathrm{m})\end{array}$ & $\begin{array}{l}\mathrm{T}\left({ }^{\circ} \mathrm{C}\right) \\
(\mathrm{m})\end{array}$ & $\begin{array}{l}\text { Depth } \\
\mathrm{T}\left({ }^{\circ} \mathrm{C}\right)\end{array}$ & $\begin{array}{l}\text { Depth } \\
(\mathrm{m})\end{array}$ \\
\hline 21.89 & 14 & 22.57 & 56 & 23.58 & 98 & 25.06 & 140 & 26.36 & 182 & 27.42 & 224 & 28.51 & 266 \\
21.89 & 16 & 22.60 & 58 & 23.65 & 100 & 25.11 & 142 & 26.41 & 184 & 27.48 & 226 & 28.59 & 268 \\
21.90 & 18 & 22.68 & 60 & 23.72 & 102 & 25.18 & 144 & 26.46 & 186 & 27.52 & 228 & 28.64 & 270 \\
21.92 & 20 & 22.69 & 62 & 23.78 & 104 & 25.24 & 146 & 26.51 & 188 & 27.58 & 230 & 28.70 & 272 \\
21.93 & 22 & 22.72 & 64 & 23.85 & 106 & 25.32 & 148 & 26.57 & 190 & 27.63 & 232 & 28.75 & 274 \\
21.94 & 24 & 22.75 & 66 & 23.95 & 108 & 25.36 & 150 & 26.62 & 192 & 27.68 & 234 & 28.81 & 276 \\
21.96 & 26 & 22.78 & 68 & 23.99 & 110 & 25.43 & 152 & 26.67 & 194 & 27.75 & 236 & 28.85 & 278 \\
21.97 & 28 & 22.82 & 70 & 24.06 & 112 & 25.49 & 154 & 26.74 & 196 & 27.78 & 238 & 28.90 & 280 \\
21.99 & 30 & 22.88 & 72 & 24.14 & 114 & 25.57 & 156 & 26.79 & 198 & 27.83 & 240 & 28.95 & 282 \\
22.02 & 32 & 22.92 & 74 & 24.21 & 116 & 25.65 & 158 & 26.85 & 200 & 27.88 & 242 & 29.01 & 284 \\
22.05 & 34 & 22.96 & 76 & 24.30 & 118 & 25.69 & 160 & 26.89 & 202 & 27.95 & 244 & 29.06 & 286 \\
22.08 & 36 & 23.02 & 78 & 24.38 & 120 & 25.76 & 162 & 26.93 & 204 & 28.00 & 246 & 29.12 & 288 \\
22.11 & 38 & 23.09 & 80 & 24.45 & 122 & 25.84 & 164 & 26.98 & 206 & 28.06 & 248 & 29.20 & 290 \\
22.15 & 40 & 23.16 & 82 & 24.52 & 124 & 25.88 & 166 & 27.04 & 208 & 28.11 & 250 & 29.28 & 292 \\
22.86 & 42 & 23.22 & 84 & 24.57 & 126 & 25.94 & 168 & 27.09 & 210 & 28.16 & 252 & 29.38 & 294 \\
22.22 & 44 & 23.28 & 86 & 24.66 & 128 & 26.02 & 170 & 27.13 & 212 & 28.21 & 254 & 29.45 & 296 \\
22.25 & 46 & 23.33 & 88 & 24.73 & 130 & 26.07 & 172 & 27.20 & 214 & 28.26 & 256 & 29.52 & 298 \\
22.28 & 48 & 23.40 & 90 & 24.77 & 132 & 26.14 & 174 & 27.25 & 216 & 28.31 & 258 & - & - \\
22.32 & 50 & 23.39 & 92 & 24.86 & 134 & 26.19 & 176 & 27.29 & 218 & 28.36 & 260 & - & - \\
22.34 & 52 & 23.47 & 94 & 24.94 & 136 & 26.23 & 178 & 27.33 & 220 & 28.42 & 262 & - & - \\
22.47 & 54 & 23.54 & 96 & 24.97 & 138 & 26.28 & 180 & 27.37 & 222 & 28.47 & 264 & - & - \\
\hline
\end{tabular}

ground surface temperature reconstruction goes to the year 2005. The obtained signal is more robust showing a warming of about $1{ }^{\circ} \mathrm{C}$ in the last century (Fig. $5 \mathrm{~b}$ ). The analysis of the subsurface thermal anomalies in other region in Morocco highlighted the same warming tendency at the ground surface of about 1 to $3{ }^{\circ} \mathrm{C}$ between 100 and 300 years ago (Rimi 2000).

The direct comparison of the meteorologic record with the borehole reconstructions over the time interval represented by the instrumental record can be a useful test to confirm the temperature changes found from the borehole temperature measurements. It must be stressed that it is not the absolute temperature that is of greatest importance, but rather that both the air and subsurface temperatures exhibit the same trends over time intervals (Chapman et al. 2004). Figure 6 shows the change in the annual average temperature from 1961 to 2006

Table 3 Characteristics of the logged boreholes. Depth: Boreholes depth (m), RTL: Range of temperature logs used for inversion (m), $\mathrm{k}$ : Thermal diffusivity $\left(\mathrm{m}^{2} / \mathrm{s}\right)$

\begin{tabular}{llllll}
\hline Borehole & Latitude $(\mathrm{N})$ & Longitude $(\mathrm{W})$ & Depth $(\mathrm{m})$ & RTL $(\mathrm{m})$ & $\mathrm{k}\left(\mathrm{m}^{2} / \mathrm{s}\right)$ \\
\hline $2952 / 12$ & $34^{\circ} 23^{\prime} 59^{\prime \prime}$ & $1^{\circ} 30^{\prime} 00^{\prime \prime}$ & 700 & $47-299$ & $0.7 .10^{-6}$ \\
$1624 / 7$ & $34^{\circ} 55^{\prime} 47^{\prime \prime}$ & $2^{\circ} 17^{\prime} 59^{\prime \prime}$ & 1300 & $14-298$ & $0.7 .10^{-6}$ \\
\hline
\end{tabular}




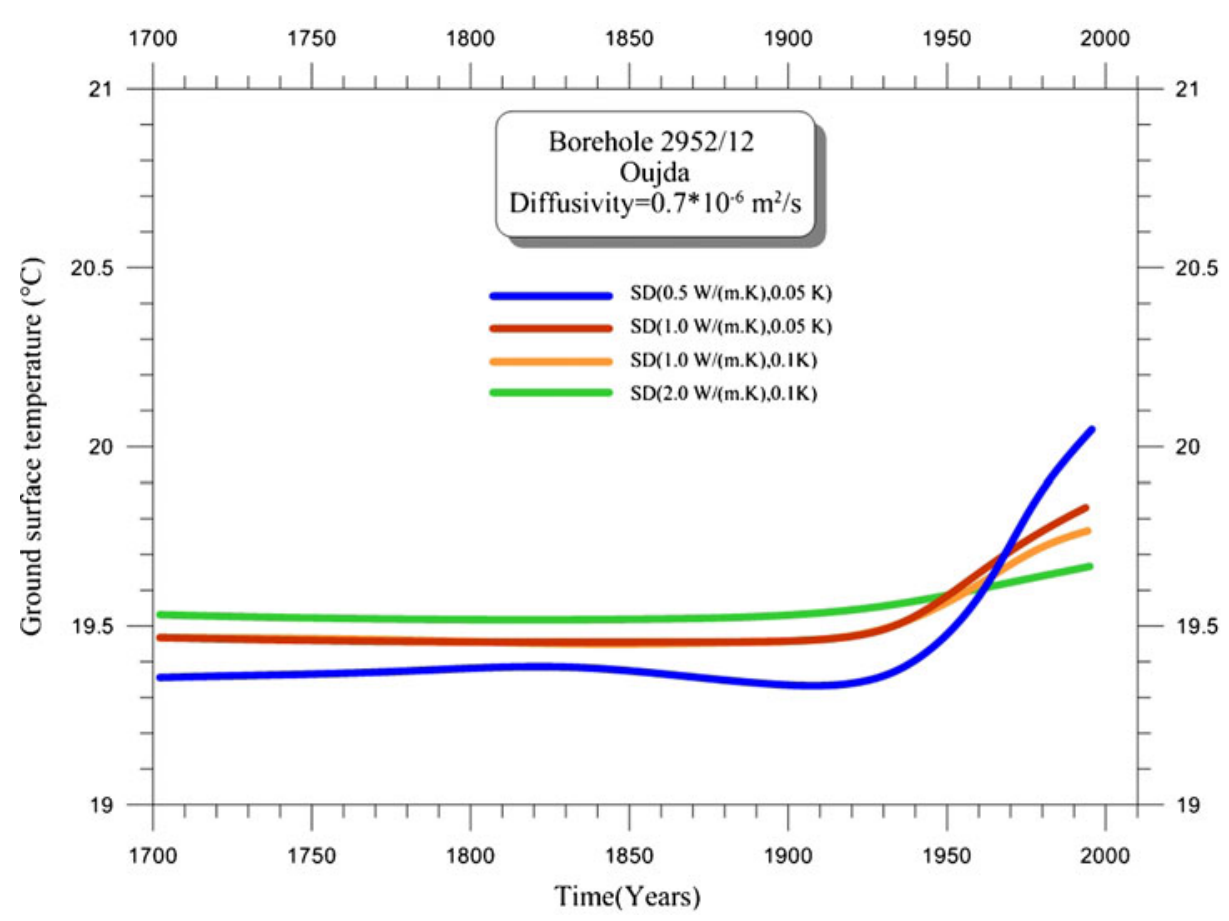

Fig. 5 a, b: History of ground surface temperature variations associated with climate changes using the functional space inversion models for the boreholes 2952/12 in Oujda and 1624/7 in Berkane region

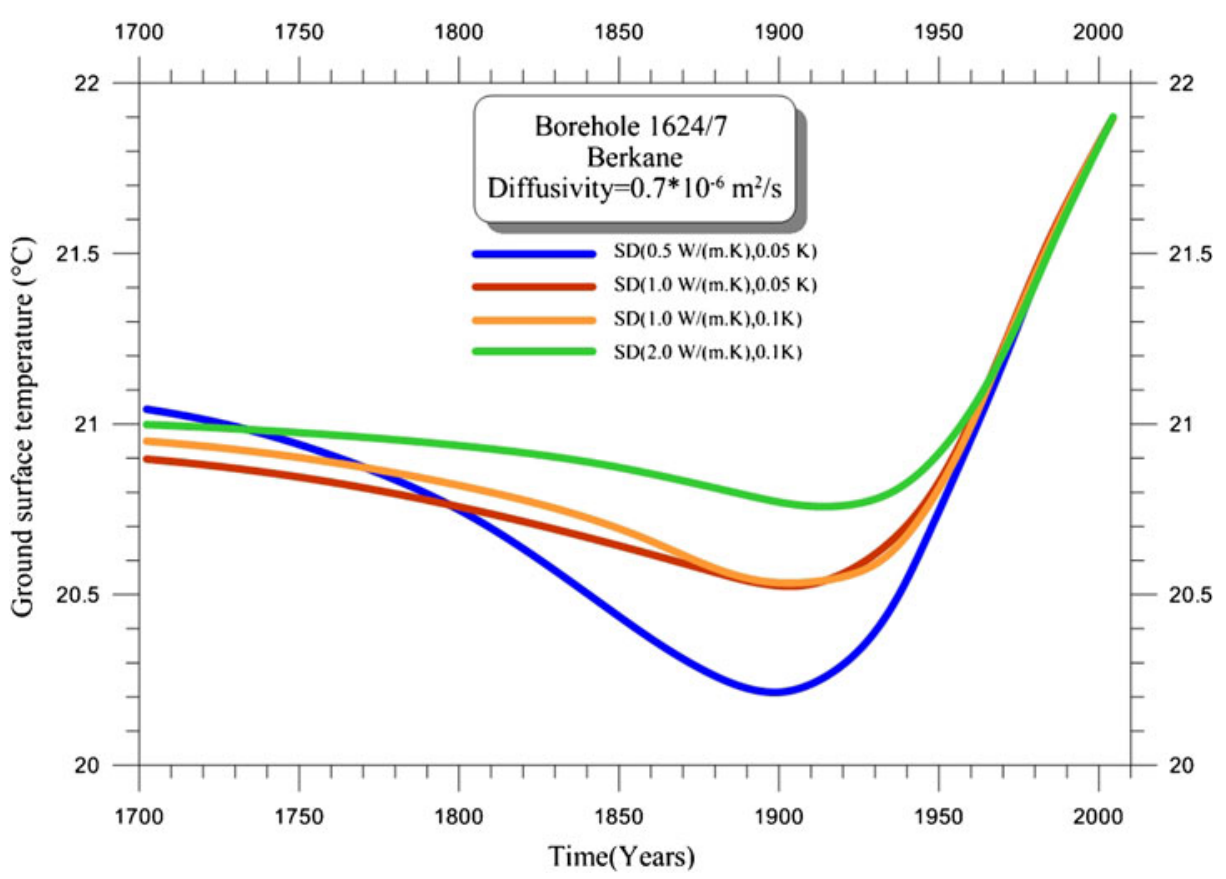

Fig. 5 (continued) 


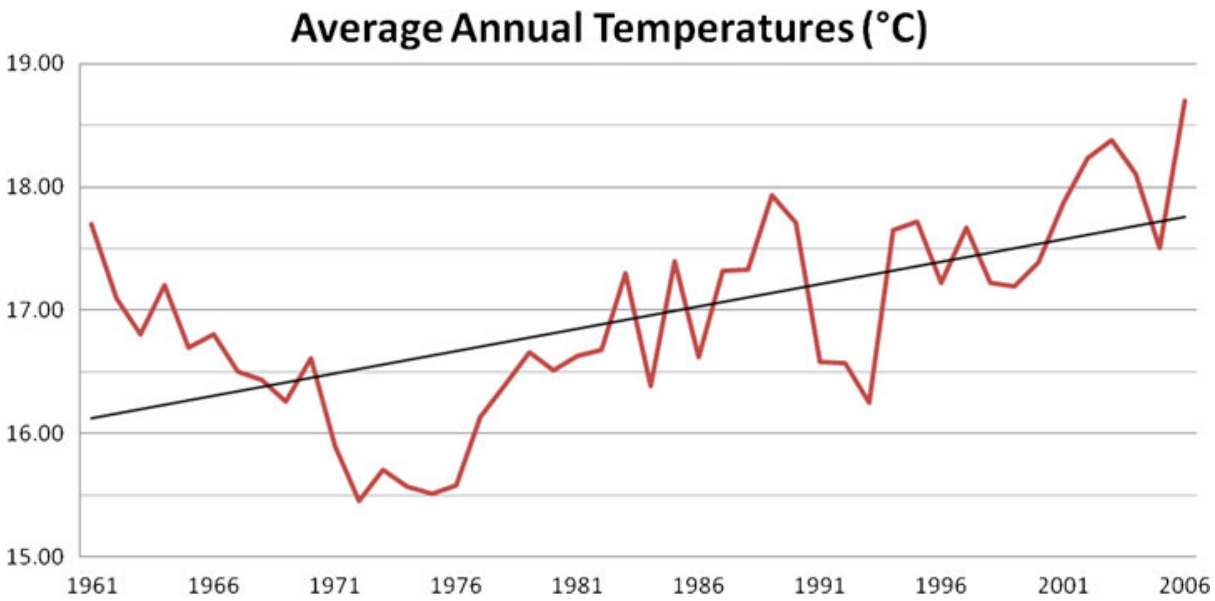

Fig. 6 Surface air temperature variation from the meteorological station of Oujda-Angad (1961 to 2006)

recorded in Oujda meteorological station $\left(34^{\circ} 46^{\prime} 48^{\prime \prime} \mathrm{N}, 1^{\circ} 55^{\prime} 48^{\prime \prime} \mathrm{W}\right)$, data shows a clear upward trend exceeding $1{ }^{\circ} \mathrm{C}$. The analysis of precipitation data from the same period show a clear variation consisting in a shift towards warmer and drier conditions in northeastern Morocco (Driouech 2010).

One of the main problems in the use of data from meteorological stations is the short duration of the surface air temperature measurement. In this case the estimate of the climate variability prior to the existence of the instrumental record can be derived from climate proxies. Cedrus atlantica ring width data were used to reconstruct the long-term changes in the Palmer Drought Severity Index (PDSI) over the past 953 years in Morocco. The reconstruction captures the dry conditions since the 1980s well and places this extreme period within a millennium-long context. (Esper et al. 2007).

\section{Conclusion}

From a set of many temperature logs, measured in northeastern Morocco, only two were found suitable for estimating the ground surface temperature history. The boreholes depth ranges from 700 to $1300 \mathrm{~m}$. The uppermost section used for inversion range from 47 to $299 \mathrm{~m}$ for the borehole 2952/12, and from 14 to $298 \mathrm{~m}$ for the borehole $1624 / 7$. The functional space inversion method was used in order to reconstruct the surface temperature past changes. The obtained result showing a warming by 0.1 to $1{ }^{\circ} \mathrm{C}$ are coherent with the air temperature record of a meteorological station in Oujda. The warming tendency is confirmed also using other climate proxies.

Acknowledgements The authors warmly thank the anonymous reviewers for their detailed and constructive criticisms, which were of great help in improving this manuscript. This work was supported by the Moroccan Portuguese CNRST-GRICES project SDT/2010 which is collaboration between the laboratory of hydrogeology and environment in the faculty of science in Oujda, the scientific institute of Rabat and the geophysical center of Evora. 


\section{References}

Bense V, Beltrami H (2007) The impact of horizontal groundwater flow and localized deforestation on the development of shallow temperature anomalies. J Geophys Res 112:F04015

Bodri L, Cermak V (2007) Borehole climatology: a new method how to reconstruct climate, Elsevier Science and Technology.

Carslaw HS, Jaeger JC (1962) Conduction of heat in solids. Clarendon, Oxford, p 510

Chapman DS, Bartlett MG, Harris RN (2004) Comment on "Ground vs. surface air temperature trends: Implications for borehole surface temperature reconstructions" by M. E. Mann and G. Schmidt. Geophys Res Lett 31:L07205. doi:10.1029/2003GL019054

Driouech A (2010) Distribution des précipitations hivernales sur le Maroc dans le cadre d'un changement climatique: descente d'échelle et incertitudes. These $164 \mathrm{pp}$.

Esper J, Frank D, Büntgen U, Verstege A, Luterbacher J, Xoplaki E (2007) Long-term drought severity variations in Morocco. Geophys Res Lett 34:L17702. doi:10.1029/2007GL030844

González-Rouco JF, Beltrami H, Zorita E, Stevens MB (2009) Borehole climatology: a discussion based on contributions from climate modeling. Clim Past 5:97-127. doi:10.5194/cp-5-97-2009

Majorowicz J, Šafanda J, Skinner WR (2004) Past surface temperature changes as derived from continental temperature logs - Canadian and some global examples of application of a new tool in climate change studies. Adv Geophys 2004:47,113-173. doi:10.1016/S0065-2687(04)47003-4

Pollack HN (2000) Huang S (2000) Climate reconstruction from subsurface temperatures. Ann Rev Earth Planet Sci 28:339-365

Rath V, González-Rouco JF, Goosse H, (2012) Impact of postglacial warming on borehole reconstructions of last millennium temperatures, Clim. Past, in press.

Rimi (2000) Evidence of recent warming in the north of Morocco from disturbed geothermal gradients. Geodinamica Acta 13(1):19-27

Shen PY, Beck AE (1991) Least squares inversion of borehole temperature measurements in functional space. J Geophys Res 96:19,965-19,979

Vasseur G, Bernard P, Van de Meulebrouk J, Kast J, Jolivet Y (1983) Holocene paleo-temperatures deduced from geothermal measurements. Palaeogeogr Palaeoclimatol Palaeoecol 43:237-259

Zarhloule Y (1999) Potentialités géothermiques du Maroc: Traitement intégré par les températures profondes et indices de surface. Doctorat d'Etat, Fac. Sci. Oujda, Maroc 153 p. 